\title{
On the economics of post-traumatic stress disorder among first responders in Canada
}

\author{
Stuart Wilson, ${ }^{*}$ Harminder Guliani, ${ }^{*}$ Georgi Boichev*
}

\begin{abstract}
There is an increasing awareness of the tragic consequences of post-traumatic stress disorder (PTSD) among first responders in Canada. There is also an increasing awareness of the lack of understanding about the economic and social costs of PTSD in Canada. This article aims to briefly review the current evidence on the prevalence rates of PTSD, the economic costs associated with PTSD, and the costs and efficacy of various treatment strategies, to provide a framework for future research on the economic analysis of PTSD. Estimates suggest that as many as 2.5 million adult Canadians and 70,000 Canadian first responders have suffered from PTSD in their lifetimes. While we could not find any evidence on the economic cost of PTSD specifically, a recent estimate suggests that mental illness in the Canadian labour force results in productivity losses of $\$ 21$ billion each year. Research from Australia suggests that expanded mental health care may improve the benefits of treatment over traditional care, and more cost-effectively. Given the methodological challenges in the existing studies and the paucity of evidence on Canada, more Canadian studies on prevalence, on the economic and social costs of PTSD, and on the costs and effectiveness of various treatment options are encouraged.
\end{abstract}

Key Words Prevalence rates, treatment, effectiveness, costs, economic analysis

Journal of CSWB. 2016 Aug;1(2):26-31

www.journalcswb.ca

\section{INTRODUCTION}

On May 13 2015, Judy Trinh of CBC News published a story titled, "PTSD a nightmare for many first responders." In that story, she wrote that 40 first responders had committed suicide since April 2014, and that "first responders have a greater risk of developing PTSD than soldiers in combat zones," as indicated by Dr Lynette Monteiro, an Ottawa psychologist (Trinh, 2015). More encouragingly, on June 25 2015, CBC News ran a story on RCMP constable Ariane Muirhead, who suffers from PTSD and experienced the stigma and embarrassment, but who accessed the RCMP's employee assistance program and is recovering. She is now raising awareness of the disorder (CBC News, 2015). The purpose of this review article is to briefly assess the literature on the scale and scope of PTSD in Canada, and to consider future work to identify the economic impact of PTSD.

\section{POST-TRAUMATIC STRESS DISORDER}

The diagnostic criteria for PTSD include the exposure to a traumatic event including death, serious injury, or violence, and the experience of repeated memories or reactions to the event. Population surveys have indicated that many individuals with anxiety disorders including PTSD do not seek help, and many of those who do seek help receive ineffective care. Research has indicated that non-psychiatric treatments made up over half of the annual costs for anxiety disorders in the US (Greenberg, Sisitsky, Kessler et al., 1999; Issakidis \& Andrews, 2002; Wang, Demler \& Kessler, 2002). And due to the similarity of symptoms, PTSD sufferers may instead be diagnosed with other disorders, including depressive disorder, substance use disorder, and conduct disorder, and may not receive appropriate treatment (Kessler, Sonnega, Bromet et al., 1995; Kessler, Lane, Shahly et al., 2005; Van Ameringen, Mancini, Paterson et al., 2008; Yaffe, Vittinghoff, Lindquist et al. 2010). The experience of a traumatic event is a risk factor for the development of physical health problems including chronic pain, neurological conditions (e.g., epilepsy), vascular conditions (e.g., cardiac disease), gastrointestinal diseases (e.g., ulcers), metabolic or autoimmune diseases (e.g., thyroid disease), and bone or joint conditions (e.g., arthritis) (Sareen, Cox, Clara et al., 2005: Table 3; Schnurr \& Green 2004). PTSD sufferers face considerable difficulty maintaining family and social relationships, increased absenteeism, and problems progressing in their education and careers (Olatunji, Cisler \& Tolin, 2007; Sayer, Carlson \& Schnurr, 2011; Schnurr, Lunney, Bovin et al., 2009). Tragically, the end result of PTSD is sometimes suicide (Afifi, Enns, Cox et al., 2008; Sareen, Cox, Clara et al., 2005; Sareen, Cox, Stein et al., 2007; Nock, Hwang, Sampson et al., 2010). 


\section{PTSD Prevalence in Canada}

Given the human consequences of PTSD, and its implications for society, it is important to get a sense of the prevalence of the disorder among the population, and among high-risk groups. Results from the most recent Canadian Community Health Survey of 2012 suggested a one-year prevalence rate of PTSD of $1.7 \%$ among the Canadian population (Statistics Canada, 2013). In comparison, the one-year prevalence rate for PTSD among US adults has been estimated at 3.5\% (Kessler, Chui, Demler et al., 2005). Hinton and Lewis-Fernandez (2011) examined prevalence rate studies conducted in other regions of the world, and found that the one-year rate in the US is higher than those in Beijing and Shanghai (0.2\%), Japan $(0.4 \%)$, Mexico and South Africa (0.6\%), and in Europe $(0.9 \%)$. These rates are identified in Figure 1.

A series of articles has identified lifetime PTSD prevalence rates for several high-risk groups including military personnel, police, corrections workers, firefighters, and paramedics. These rates range from $8 \%$ to $32 \%$, as shown in Figure 2. Given these estimates, and the estimates of the populations of these at-risk groups, one might provide a rough estimate of the number of individuals who have experienced PTSD in their lifetime. Table I illustrates that 2.5 million Canadians, between 25 and 46 thousand full-time first responders, and another 12 to 23 thousand volunteer first responders, may have experienced PTSD in their lifetimes, given the estimates of prevalence

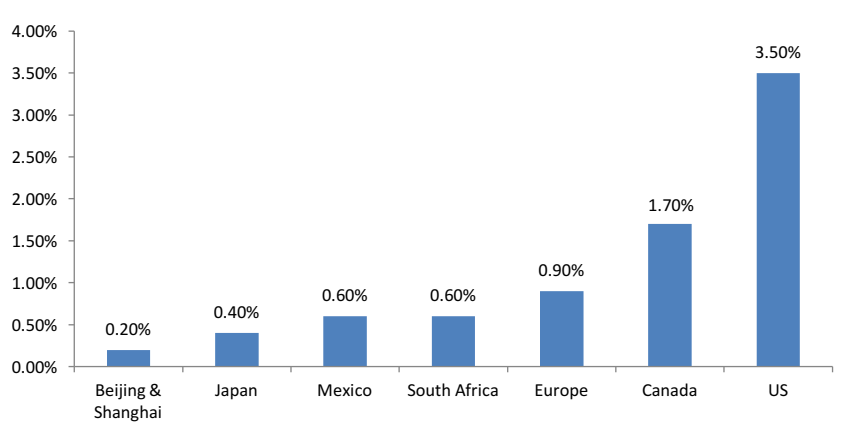

FIGURE 1 One-Year PTSD Prevalency Rates: General Population. Sources: Kessler, Chui, Demler et al.(2005); Hinton \& Lewis (201 1); Statistics Canada (2013).

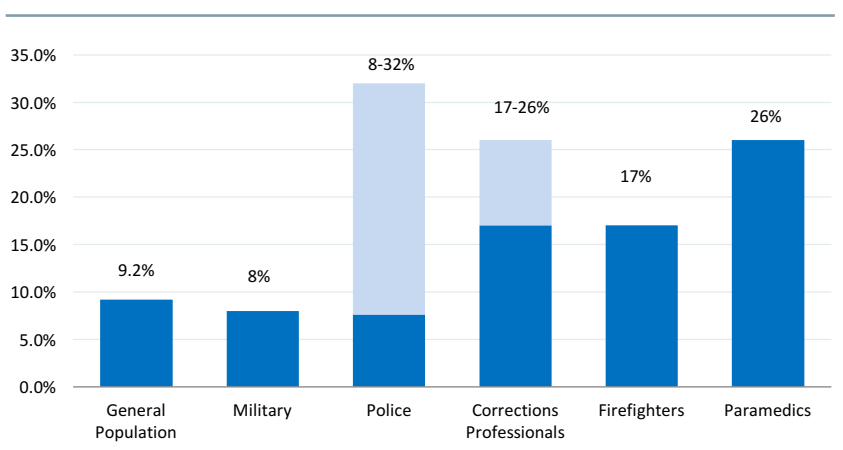

FIGURE 2 Lifetime PTSD Prevalence Rates: Specified Canadian Populations.

Sources: Van Ameringen, Mancini, Paterson et al. (2008); Boulos \& Zamorski (2013): Marchand, Boyer, Martin et al. (2010); Asmundson \& Stapleton (2008); Rosine (1992); Stadnyk (2004): Corneil, Beaton, Murphy et al. (1 999); Regehr, Goldberg \& Hughes (2002) rates and the size of specific population groups in 2010 (see Table I).

Now, there are several caveats in using these prevalence estimates, given the limited number of studies, and given their methodology and intent. The first caveat to note here is that some surveys rely on a simple self-assessment question like, "Do you have post-traumatic stress disorder?" (Statistics Canada, 2013), while others use symptom scale instruments (Van Ameringen, Mancini, Paterson et al., 2008), or a review of clinical results (Boulos \& Zamorski, 2013). The second caveat involves the sample representativeness of survey respondents; while two of the aforementioned studies use samples considered representative of the population, other studies make use of convenience samples consisting of a small number of individuals who agreed to participate in a study (Regehr, Goldberg \& Hughes, 2002; Marchand, Boyer, Martin et al., 2011). The third caveat is that different studies present different time periods for which the prevalence of PTSD is identified; these periods may be for one month, six months, one year, or "lifetime" (i.e., up until this point in time), for which rates are presented, and these rates are not directly comparable; this makes it difficult to assess how many individuals should have received treatment in any given period. Overall, although there are some useful estimates of PTSD prevalence rates in Canada, for an accurate understanding of the impact of PTSD in Canada, representative surveys of both the general and at-risk populations using acceptable diagnostic instrument questionnaires to derive one-year prevalence rates are required in moving forward a research agenda to estimate the annual costs of PTSD in Canada, and among first responders.

\section{Treatment and Prevention Strategies}

There have been many recent developments in the treatment of PTSD as employers and health care practitioners have become increasingly aware of the challenges PTSD presents. Proactive interventions, within the first few hours of the trauma, are seen to be crucial for the prevention or reduction of post-traumatic anxiety as they could help victims regain emotional control, restore interpersonal communication, and encourage the return to normal life (Zohar, Sonnino \& Juven-Wetzler, 2009). Several immediate and early psychological interventions have been specifically designed for this purpose, including psychological debriefing, psychoeducative information, and stress management (Agorastos, Marmar \& Otte, 2011). However, the efficacy of single and multiple-session psychological debriefing, in preventing or reducing the intensity of PTSD is inconclusive, or may even be compromised by adverse effects (Agorastos, Marmar \& Otte, 2011; Jeannette \& Scoboria, 2008; Roberts, Kitchiner, Kenardy et al., 2009; Rose, Bisson, Churchill et al., 2002).

The majority of mental health interventions, including exposure-based Cognitive Behaviour Therapy (CBT), cognitive restructuring, and stress inoculation therapy (a form of CBT), place greater emphasis on cognitive strategies to help people alter their destructive thoughts and behaviours resulting from a traumatic event. Internet-based CBTs are also gaining popularity because they can be administered remotely while preserving identity and affordability. A thorough review of the current literature on various mental disorders by Katzman, Bleau, Blier et al. (2014) provides good 
TABLE I Canadian PTSD prevalence estimates

\begin{tabular}{|c|c|c|c|}
\hline Group & "Lifetime" Prevalence Rate Estimates ${ }^{a}$ & 2010 Population $^{b}$ & Prevalence Estimates \\
\hline Adult Population & $9.2 \%$ & $27,259,525$ & $2,507,876$ \\
\hline Military & $8 \%$ & $30,513^{c}$ & 2,441 \\
\hline Police Officers ${ }^{d}$ & $8 \%-32 \%$ & 85,050 & $6,464-27,216$ \\
\hline Corrections Professionals & $17 \%-26 \%$ & 23,965 & $4,074-6,231$ \\
\hline Firefighters & $17 \%$ & 34,390 & 5,846 \\
\hline Paramedics & $26 \%$ & 26,760 & 6,958 \\
\hline First Responders & $(12 \%-23 \%)$ & 200,678 & $25,783-46,251$ \\
\hline Volunteer First Responders & $(12 \%-23 \%)$ & $100,000^{e}$ & $(12,000-23,000)$ \\
\hline
\end{tabular}

a See Figure 2 for sources for prevalence rates.

b 2011 National Household Survey, Employment by Occupation.

c Military population having served in Afghan-related missions from 2001 to 2008.

d Except commissioned officers.

e Canadian Interoperability Technology Interest Group (CITIG) estimate.

evidence on the efficacy of several CBT approaches for the management of chronic PTSD. It is worth noting that benefits of psychological treatments such as cognitive and exposure therapies are maintained over a long period of time.

Pharmacological interventions, instead, are short-term treatments of PTSD aiming to improve the debilitating effects of brain disorder due to traumatic events. Various antidepressants that have good evidence for efficacy as first-line agents in treating PTSD include selective serotonin reuptake inhibitors (SSRIs) such as paroxetine, and serotonin norepinephrine reuptake inhibitors (SNRIs) such as venlafaxine XR, but there is little evidence supporting the use of pharmacological interventions for the prevention of PTSD (Haugen, Evces, Weiss et al., 2012; Katzman, Bleau, Blier et al., 2014).

In Canada, various occupation/employer-specific mental health support services use a combination of the aforementioned interventions to educate and build awareness of mental health issues for employees. The Royal Canadian Mounted Police (RCMP), for instance, provides various support services such as peer-to-peer support programming, psychotherapeutic services, periodic health assessments, counselling services through Health Canada's Employee Assistance program, benefits from provincial workers compensation boards, Operational Stress Injury clinics, Occupational Health and Safety Services Offices, and Operational Stress Injury Social Support services to support members' health, safety, and fitness for duty (RCMP, 2016). Similarly, Toronto Emergency Medical Services facilitate a host of psychological support systems that includes a designated full-time psychologist, a peer support team, an employee assistance program, and extended health benefits (Paramedic Chiefs of Canada, 2014). Alberta Emergency Medical Services have a full-time, critical-incident stress management coordinator and offer a comprehensive pre-incident to post-incident program (Paramedic Chiefs of Canada, 2014). More recently, the Manitoba government amended Workers Compensation Board regulations to ensure timely access to compensation and support services to all eligible workers diagnosed with PTSD, with the long-term goal of reducing the stigma attached to mental illness (WCB, 2016).

While a substantial amount of literature examines the efficacy of various psychological and pharmacological interventions, very few of these studies examine treatment strategies among first responders. PTSD treatment studies from Canada are virtually non-existent. The Canadian clinical practice guidelines for the treatment of PTSD utilize global studies on efficacy and effectiveness (Katzman, Bleau, Blier et al., 2014). Moreover, the facilitators and barriers in accessing treatment services among first responders in Canada are also unknown. Thus, there is a need to evaluate the effectiveness of various treatment and prevention interventions for PTSD among first responders in Canada. As many psychological interventions are not publicly funded, it is crucial to identify and prioritize effective interventions to ensure timely access to effective treatment and to contain long-term health care costs. We therefore encourage the development of clinical trials in Canada which evaluate the level of impairment of individuals suffering from PTSD, and which track individuals who are being treated and who are not being treated, to compare their outcomes at work and in their communities with those who are not suffering from PTSD.

\section{The Costs of Treating PTSD}

To our knowledge, there has been no comprehensive study of the costs of treating PTSD in Canada. A review article by Konnopka, Leichsenring, Leibing et al. (2009) identified and reviewed 20 cost-of-illness studies and 11 cost-effectiveness studies for treatment of anxiety disorders, which were published between 2000 and 2008. Two of those studies assessed the cost of treatment for PTSD.

The study by Marciniak, Lage, Dunayevich et al. (2005) focused on the costs of treating various anxiety disorders, over a three-year period from 1996 to 1999 in the United States, while accounting for comorbidities. Their estimates revealed that the marginal treatment cost of a patient having at least one anxiety disorder, after controlling for demographic and other disease states, is US\$6,475 over a maximum of three years during the study period. The corresponding marginal treatment costs reported for any one isolated anxiety disorder are also sizable- the estimated cost for PTSD was $\$ 3,940$, with a $\$ 1,945$ cost for depression as a comparative example, during the three-year study period.

Issakidis, Sanderson, Corry et al (2004) was the only cited study to examine the cost-effectiveness of existing treatment 
practices vs. optimal treatment for PTSD. The major focus of the study was to estimate the reduction of the social burden of mental disorders if all those who were currently being treated in Australia were to receive the evidence-based optimal care treatment as defined by professional consensus and the clinical trial literature. For the most part, evidence-based optimal care involved a shift from an over-reliance on the general health sector and consultations with general practitioners, toward an increased use of mental health services, and more specifically for PTSD, toward an increase in the use of CBT.

For the estimated 129,211 Australians who received treatment with PTSD as the principal complaint over the 1997/98 period, total treatment costs amounted to AU\$158 million, or AU\$1,224 per case that year. The effectiveness of the treatment was estimated to be 6.7 thousand years lived disabled averted, for a cost of AU\$65 per day lived disabled averted. A shift toward the optimal care strategies was estimated to cost AU\$149 million (AU\$1,155 per case), with a higher estimated total of 9.5 thousand years lived disabled averted, for a cost estimate of AU $\$ 43$ per day lived disabled averted. Total estimated savings to the health care system was AU\$9 million with substantial improvements in treatment efficacy. Given the authors estimated that $64 \%$ of those diagnosed with PTSD received treatment consistent with the evidence-based optimal care, one might estimate that the cost savings for optimal care would be much higher for a health care system in which fewer sufferers received the optimal care treatment.

\section{The Economic Costs of PTSD and Illness}

While the cost of treating PTSD sufferers is an intuitive starting point to assess the costs of PTSD, it is not the starting point for economic analyses. From an economics perspective, a cost analysis of illness measures the costs imposed by a disease to an untreated ill individual relative to that of a healthy individual. These costs encompass those associated with the loss in well-being and with lost productivity and foregone earnings. The cost-of-illness approach widely used in the health literature is, in general, compatible with this framework, but its main limitation is that it does not disentangle the cost of treatment from the cost of illness in a number of respects.

The cost-of-illness approach reports both direct and indirect costs. The direct costs include the accounting costs of medical expenses on treating an illness (e.g., hospital stay, physicians' fees, lab tests, and prescription drugs). From an economic standpoint, however, these direct costs would be more appropriate as a cost component of the cost-effectiveness of treatment which accrues benefits to the patient. This approach monetizes the improvement of a patient's well-being relative to the accounting costs incurred in treatment, in which a key individual characteristic is the responsiveness to treatment.

The indirect costs in cost-of-illness studies tend to capture the productivity differential between a treated ill individual and a healthy individual. The critique from an economic standpoint is that these indirect costs are underestimates of the indirect cost of the illness since they include benefits of treatment. This issue is depicted in Figure 3. The economic cost-benefit analysis of illness would use the productivity differential between an untreated ill individual and a healthy individual, depicted in the third bar in the chart, not the differential between a treated ill individual

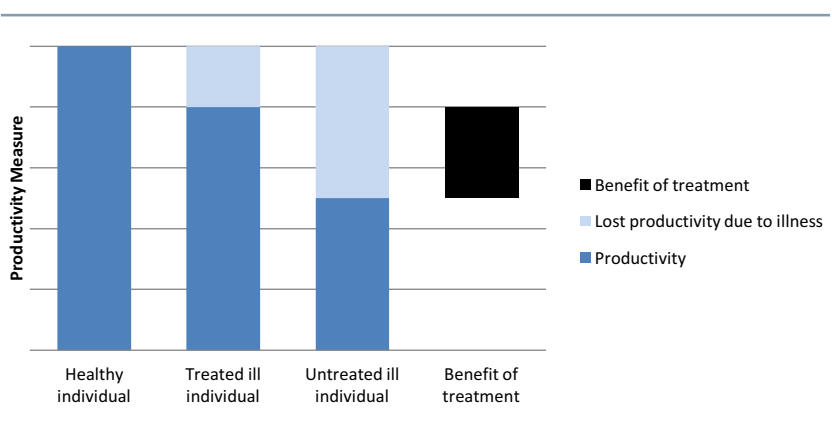

FIGURE 3 Productivity Loss Estimate for the Cost of IIness ${ }^{a}$

a The estimate of the productivity loss due to illness will be underestimated by using the estimate from the treated ill individual indicated by the light-shaded area of the second bar from the left The more appropriate estimate of the productivity loss due to illness is indicated by the light shaded area of the third bar from the left. The benefit of treatment is indicated by the difference between the two light-shaded areas, which is noted by the additional black bar.

and a healthy individual, depicted in the second bar. The corresponding analysis of treatment would assess the costs of the treatment versus the productivity differential between a treated ill individual and an untreated ill individual (the black bar in Figure 3).

How serious is the economic impact of PTSD in Canada? While we were unable to uncover any report specific to PTSD, a study conducted by the Conference Board of Canada (2012) from a sample of the working-age population suggested that the costs incurred from mental health illnesses are sizable with respect to both labour costs and GDP. Mental illness was estimated to cost Canada $\$ 20.7$ billion annually, or $1.3 \%$ of GDP, due to lost labour force participation of almost 452,000 workers stemming from the six most common conditions afflicting the working-age population (depression, dysthymia, bipolar disorder, social phobia, panic disorder, and agoraphobia). There appears to be a feedback effect of economic insecurity that worsens mental illness prevalence rates and severity. Some of the resulting secondary effects, in particular on government budgets, are higher spending on social programs and lost income tax revenue.

This Conference Board study used a survey in which respondents were asked to self-assess their mental health, to determine the prevalence rate for each illness. A key methodological contribution is that the survey also focused on the degree of debilitation of respondents, using selections such as "able to work part time" and "able to work with reduced function", to estimate the economic cost of illness for partially debilitated individuals who are part of the labour force, as well as for fully debilitated individuals who are not. The study provides a useful methodological framework for estimating the economic costs of illness and overcomes some empirical challenges. However, illness prevalence rates and the degree of debilitation might be more accurately estimated with diagnostic instruments or clinical studies.

The methodology of the Issakidis, Sanderson, Corry et al. (2004) study referenced in the previous section could conceivably be used to assess the economic costs of anxiety disorders. Of particular interest to economists are the estimates for the Years Lived with Disability (YLD) component of the Disability Adjusted Life Year (DALY) measure of the population disease burden of PTSD, and the YLD averted measures identified in meta-analyses of pharmacological and psychological treatments as defined by the randomized controlled trial 
literature. These would help provide estimates of the impact of the disability on productivity and the quality of life, and of the economic costs of untreated and treated PTSD.

Overall, the cost-of-illness approach provides estimates indicating that mental illness resulting from strains at the workplace pose sizable economic costs. These estimates have the potential to be further refined provided that data sources are improved in a number of respects. First, they must distinguish between healthy, treated ill individuals, and untreated ill individuals. Second, the surveys and clinical trials must be of representative populations, and also address the concern plaguing current surveys of high non-response rates which are correlated with the health status of the non-respondents. Questionnaires should include a larger share of objectivebased and diagnostic questions, from which could be inferred information about the length, severity and progression of the illness. Questions about the impact of illness on work, productivity, and income, and on personal relationships and quality of life could also be included.

\section{CONCLUSION}

PTSD is taking its toll on our first responder community. Canada is collectively suffering great losses with tragic consequences, and with other human and economic losses. However, we do not fully understand the prevalence of PTSD in the community, nor its economic and social impact. It is possible that as many as 2.5 million adult Canadians and 70,000 first responders have suffered from PTSD in their lifetimes. A recent study has estimated that productivity losses alone due to mental illness cost the Canadian economy $\$ 20.7$ billion annually for a half-million workers. Research conducted in Australia has suggested that, while the traditional health sector provides beneficial service to those seeking help, mental health care can improve the benefits, and more cost-effectively. Thus, there is a need for more research in Canada on PTSD to address some of the following questions:

What is the epidemiology of PTSD among first responders in Canada?

What are the facilitators and barriers in accessing mental health services among first responders in Canada? Are there any inter- and intra-regional variations in accessing these services (e.g., by the type of care provider, or by occupation)?

- What is the economic cost of PTSD-related illness in Canada? Given the methodological challenges in the existing studies identified in the previous sections, a better estimate of direct and indirect cost of mental illness in Canada is essential.

What is the per-patient cost of treating PTSD in Canada? What is the cost-effective way of providing psychological services (e.g., by public or private providers and/or in individual or group formats)? How cost-effective are employer support programs in preventing PTSD symptoms?

A starting point to answer some of these questions would be to develop a systematic approach to collect and analyze comprehensive clinical and economic data. Representative longitudinal surveys tracking the general population and the first responder community over a specified period of time, ideally one year, need to be conducted with diagnostic assessment questionnaires to identify the scope and scale of PTSD. These surveys would need to identify the proportion of individuals who seek treatment and those who do not. They would need to assess the impact of the disorder on their productivity and labour supply, in order to assess the economic and social costs of the disorder. They would need to track costs of various treatment options, and their benefits, in order to assess their effectiveness and to help refine treatment options. A collaborative effort between researchers and different organizations, such as the RCMP and the Paramedic Chiefs of Canada, and insurers, such as the Workers Compensation Board, might help to develop such longitudinal datasets to better identify the economic costs of PTSD-related illness and to provide meaningful estimates to Canadian decision-makers. PTSD is treatable and its impact on society may be reduced through research and evidence-based policy.

\section{ACKNOWLEDGMENTS}

The authors acknowledge constructive conversations with and encouragement from Hirsch Greenberg, Ron Camp, and Nick Carleton from the University of Regina, Vince Savoia from TEMA Conter, Eric Torunski from the Canadian Interoperability Technology Interest Group (CITIG), Steve Palmer from the Collaborative Centre of Justice and Safety, and from the Editors and Referees of this Journal. Material in this article was presented in a PTSD First Responders and Community Workers Forum workshop prior to the 35th Canadian Congress on Criminal Justice, held in Regina SK, on September 30, 2015. Any errors of fact and interpretation remain solely those of the authors.

\section{CONFLICT OF INTEREST DISCLOSURES}

The authors do not have any known conflicts of interest.

\section{AUTHOR AFFILIATIONS}

*Department of Economics, University of Regina, Regina, SK, Canada.

\section{REFERENCES}

Afifi, T.O., Enns, M.W. Cox, B.J., Asmundson, G.J.G. Stein, M.B., \& Sareen, J. (2008). Population attributable fractions of psychiatric disorders and suicide ideation and attempts associated with adverse childhood experiences. Am J Public Health, 98(5):946-952.

Agorastos, A., Marmar, C. R., \& Otte, C. (2011). Immediate and early behavioral interventions for the prevention of acute and posttraumatic stress disorder. Current Opinion in Psychiatry, 24(6):526-532.

Asmundson, G.J. \& Stapleton, J.A. (2008). Associations between dimensions of anxiety sensitivity and PTSD symptom clusters in active-duty police officers. Cognitive Behaviour Ther, 37(2):66-75.

Boulos, D. \& Zamorski, M.A. (2013). Deployment-related mental disorders among Canadian Forces personnel deployed in support of the mission in Afghanistan, 2001-2008. Can Med Assoc J, 185(11):E545-E552.

CBC News. (2015, June 25). PTSD a treatable injury, says recovering Saskatchewan Mountie. Regina: CBC News. Available from: http://www.cbc.ca/news/canada/saskatchewan/ptsd-a-treatableinjury-says-recovering-saskatchewan-mountie-1.3127411 Accessed on April 4, 2016

Conference Board of Canada. (2012). Mental health issues in the labour force: reducing the economic impact on Canada. Publication 13-037. Ottawa, ON: Conference Board of Canada.

Corneil, W., Beaton, R., Murphy, S., Johnson, C., \& Pike K. (1999). Exposure to traumatic incidents and prevalence of posttraumatic stress symptomatology in urban firefighters in two countries. J Occupat Health Psychol, 4(2): 131-141. 
Greenberg, P.E., Sisitsky, T., Kessler, R.C., Finkelstein, S.N., Berndt, E.R., Davidson, J.R., , \& Fyer, A.J. (1999). The economic burden of anxiety disorders in the 1990s. J Clin Psychiatry, 60(7), 427-435.

Haugen, P.T., Evces, M., \& Weiss, D.S. (2012). Treating posttraumatic stress disorder in first responders: a systematic review. Clin Psychol Rev, 32(5): 370-380.

Hinton, D. \& Lewis-Fernández, R. (2011). The cross-cultural validity of posttraumatic stress disorder: implications for DSM-5. Depression and Anxiety 28(9):783-801

Issakidis, C. \& Andrews, G. (2002). Service utilisation for anxiety and in an Australian community sample. Soc Psychiatry Psychiatr Epidemiol, 37(4),153-163.

Issakidis, C., Sanderson, K., Corry, J., Andrews, G., \& Lapsley, H. (2004). Modelling the population cost-effectiveness of current and evidencebased optimal treatment for anxiety disorders. Psychological Med 34(1): 19-35

Jeanette, J.M. \& Scoboria, A. (2008). Firefighter preferences regarding postincident intervention. Work \& Stress, 22(4):314-326.

Katzman, M.A., Bleau, P., Blier, P., Chokka, P., Kjernisted, K., \& Van Ameringen, M. (2014). Canadian anxiety disorders guidelines initiative: Clinical practice guidelines for the management of anxiety, posttraumatic stress and obsessive-complusive disorders. BMC Psychaitry, 14(1):51.

Kessler, R.C., Sonnega, A., Bromet E., Hughes, M., \& Nelson, C.B. (1995). Posttraumatic stress disorder in the National Comorbidity Survey. Arch Gen Psychiatry, 52(12):1048-1060.

Kessler, R.C., Chui, W.T., Demler, O., \& Walters, E.E. (2005). Prevalence, severity, and comorbdity of 12-months DSM-IV disorders in the National Comorbidity Survey Replication. Arch Gen Psychiatry, 62(6):617-627.

Kessler, R.C., Lane, M.C., Shahly, V., \& Stang, P.E. (2005). Accounting for comorbidity in assessing the burden of epilepsy among US adults: results from the National Comorbidity Survey Replication (NCS-R). Mol Psychiatry, 17(7):748-758.

Konnopka, A., Leichsenring, F. Leibing, E., \& Konig, H.H. (2009). Cost-ofillness studies and cost-effectiveness analyses in anxiety disorders: A systematic review. J Affective Disorders, 114(1-3):14-31.

Marchand, A., Boyer, R. Martin, M., \& Nadeau, C. (2010). Facteurs previsionnels du development de l'etat de stress post-traumatique a la suite d'un evenement traumatique chez les policies: volet retrospectif. IRSST Report R-633. Montreal, QC: IRSST.

Marciniak, M.D., Lage, M.J., Dunayevich, E., Russell, J.M., Bowman, L., Landbloom, R.P., \& Levine, L.R. (2005). The cost of treating anxiety: the medical and demographic correlates that impact total medical costs. Depression and Anxiety 21(4):178-184.

Nock, M.K., Hwang, I., Sampson, N.A., \& Kessler, R.C. (2010). Mental disorders, comorbidity and suicidal behavior: results from the National Comorbidity Survey Replication. Mol Psychiatry, 15(8):868-876.

Olatunii, B.O., Cisler, J.M., \& Tolin, D.F. (2007). Quality of life in the anxiety disorders: a meta-analytic review. Clin Psychol Rev, 27(5):572-581.

Paramedic Chiefs of Canada (PAC). (2014). Operational stress injury in paramedic services: A briefing to the paramedic chiefs of Canada. Ad-hoc committee on operational stress injury. Ottawa, ON: PAC. Available at: http://www.paramedicchiefs.ca/docs/bcs/PCC_Ad_hoc_Committee_on_Stress_Injury_Report.pdt

Regehr, C., Goldberg, G., \& Hughes, J. (2002). Exposure to human tragedy, empathy, and trauma in ambulance paramedics. Am J Orthopsychiatry, 72(4):505-513
Roberts, N., Kitchiner, N., Kenardy, J., \& Bisson, J. (2009). Multiple session early psychological interventions for the prevention of posttraumatic stress disorder. Cochrane Database of Systematic Reviews, 3: CD006869.

Rose, S.C, Bisson, J., Churchill, R., \& Wessely, S. (2002). Psychological debriefing for preventing post traumatic stress disorder (PTSD). Cochrane Database of Systematic Reviews 2(2):CD000560.

Rosine, L. (1992). Exposure to critical incidents: What are the effects on Canadian correctional officers? CSC Forum, 4(1):31-36. Archived at http://www.csc-scc.gc.ca/research/forum/e041/e041m-eng.shtml Accessed on August 3, 2015.

Royal Canadian Mounted Police (RCMP). 2016. Mental Health services available to RCMP employees. Ottawa, ON: RCMP. Available at: http:// www.rcmp-grc.gc.ca/fam/ptsd-tspt-eng.htm

Sareen, J., Cox, B. J., Clara, I., \& Asmundson, G.J.G. (2005). The relationship between anxiety disorders and physical disorders in the U.S. National Comorbidity Survey. Depression and Anxiety, 21 (4):193-202.

Sareen, J, Cox, B.J., Stein, M.B., Afifi, T.O., Fleet, C., \& Asmundson, G.H.G. (2007). Physical and mental comorbidity, disability, and suicidal behavior associated with posttraumatic stress disorder in a large community sample. Psychosomatic Med, 69(3):242-248.

Sayer, N.A., Carlson, K., \& Schnurr, P. (2011). Assessment of functioning and disability in individuals with PTSD. In Clinical manual for the management of posttraumatic stress disorder (pp 255-287). Benedek D, \& Wynn GH (Eds.). Arlington, VA: American Psychiatric Association Publishing

Schnurr, P., \& Green, B. (2004). Trauma and health: Physical health consequences of exposure to extreme stress. Washington, DC: American Psychological Association.

Schnurr, P., Lunney, C.A., Bovin, M.J., \& Marx, B.P. (2009). Posttraumatic stress disorder and quality of life: extension of findings to veterans of the wars in Iraq and Afghanistan. Clin Psychol Rev 29(8):727-735.

Stadynk, B. (2004). Posttraumatic stress disorder, violence and quality of life in Saskatchewan corrections workers (MA Thesis). University of Regina, Regina, SK.

Statistics Canada. (2013). Canadian Community Health Survey, 2012: Mental health component [public-use microdata file]. Ottawa, ON: Statistics Canada. Health Statistics Division, Data Liberation Initiative [producer and distributor].

Trinh, J. (2015, May 13). PTSD a nightmare for many first responders. Ottawa, $\mathrm{ON}$ : CBC News. Available from: http://www.cbc.ca/news/canada/ ottawa/ptsd-a-nightmare-for-many-first-responders-1.3070927 Accessed on April 4, 2016.

Van Ameringen, M., Mancini, C., Paterson, B., \& Boyle, M.H. (2008). Post-Traumatic Stress Disorder in Canada. CNS Neurosci Therapeut $4(3): 171-181$

Wang, P.S., Demler, O., \& Kessler, R.C. (2002). Adequacy of treatment for serious mental illness in the United States. Am J Public Health, 92(1),92-98

Workers Compensation Board of Manitoba. (2016). Policy: 44.05.30-Adjudication of psychological injuries. Winnipeg, MB: WCB. Available at: http://www.wcb.mb.ca/adjudication-of-psychological-injuries

Yaffe K, Vittinghoff E, Lindquist K, Barnes, D., Covinsky, K., Neylan, T., ... \& Marmar, C. (2010). Posttraumatic stress disorder and risk of dementia among US veterans. Arch Gen Psychiatry, 67(6):608-613.

Zohar, J., Sonnino, R., Juven-Wetzler, A., \& Cohen, H. (2009). Can posttraumatic stress disorder be prevented? CNS Spectr, 14(1 Suppl 1):44-51. 